\title{
HONEYBEES: THE POLLINATOR SUSTAINING CROP DIVERSITY
}

J agadish Bhakta Shrestha (Msc) ${ }^{18}$

\begin{abstract}
Importance of honeybees as prime pollinators for continual maintenence of crop-diversity and need of their conservation for sustainable agriculture is highlighted based on literature review. Somatic, reproductive and adaptive heterosis or hybrid effects that occur in plant progeny as a result of natural cross-pollination by honeybees brings about significant qualitative and quantitative changes in the economic and biological characteristics of crop plants. Honeybees often facilitate genetic enrichment of native plants through crosspollination offering to their varietal development and adaptation in the changing environment. The natural environment is required to provide bees with habitat or nesting sites. Promotion of organic farming and integrated pest management programs are necessitated.
\end{abstract}

Keywords: Eco-system, honeybees, pollinators, cross-pollination, sustainable agriculture.

\section{INTRODUCTION}

Many cultivated crops do not yield seeds or fruits without cross-pollination of their flowers by pollinators such as honeybees and other insects. With regard to bees' contributions, about one-third of our total diet comes directly or indirectly from bee-pollinated crop plants (Hoopingarner and Waller, 1992). It is worthy to highlight the role and contributions of honeybees towards saving certain plant and animal species and in turn saving the collapsing eco-systems or reversing desertification for sustainable agriculture. The discussion follows based on literature review to help promote the conservation and protection of honeybees by updating knowledge and expanding awareness regarding the importance of the pollinators.

\section{THE ECOLOGICAL RELATIONSHIPS SUSTAINING AGRICULTURE}

Mutually beneficial ecological relationships have been established between bees and plants. There are about 250 thousand species of flowering plants on the earth, many of which have amazingly complex relationships to bees and other pollinators including flies, beetles, moths, butterflies, birds and bats (Meeuse, 1961; Dowden, 1964). Cross-pollination by honeybees provides the plant species with greater genetic variability in the offspring than that by selfpollination. The genetic variability thus created gives the plant species greater opportunity to produce new varieties enabling them to adapt to new environments and to occupy different ecological areas (Verma, 1992). Seeds from cross-pollination have greater potentials for survival of the plant species, because the genetic interchanges add to the adaptations by plant species to new and changing environments.

Somatic, reproductive and adaptive heterosis or hybrid effects occur in plant progeny due to cross-polination. Such effects, either in a single way or in different combinations, bring about significant qualitative and quantitative changes in the economic and biological characters of plants (Verma, 1992). Numerous cultivated crops are not able to set seeds or produce fruits without cross-pollination of their flowers by honeybees or other wild insects. Cross-pollination

${ }^{18}$ Officiating Program Director, Directorate of Industrial Entomology Development, Harihar Bhawan Phone: 9841 268265, Email: jagadishbshrestha@gmail.com 
of entomophilies crops by honeybees is one of the most effective and cheap methods of increasing their yield or quality of their products. Diverse agronomic practices such as the use of manure, fertilizers, pesticides and irrigation may not bring about desired results without the use of honeybees to enhance the productivity levels of different cultivated crops through pollination. Not only the self-sterile varieties require cross-pollination, but also the selffertile forms need it by means of which they are able to produce more and better quality seeds and fruits if pollinated preferably by honeybees or by other insects. Moreover, genetic enrichment of plants is essential to acclimatize them to changing habitat. Thus bees, as pollinator, contribute to sustenance of biodiversity.

In spite of the great economic and biological importance of honeybees as pollinators of agricultural crops, it has yet not been made an integral part of agriculture and forest management in the developing countries (Verma, 1992).

\section{CONCLUSIONS}

It is necessary to increase our knowledge and understanding of what a potent force the honeybee is in food production and human nutrition. General public and policy-makers should be aware of the contribution of pollination or of the role played by insects including honeybees in pollination in order to protect and conserve these pollinators. Honeybees are natural and most efficient pollinators of native plants, thus indispensable for the maintenance of plant bio-diversity and sustainable agriculture.

Considering the pollinator's economic and biological significance, pollination activities with honeybees should be introduced in crop production. When planning an agro-forestry program, the selection of forage plants especially for honeybees should be taken into consideration. Planting of different species not only protects the pollinators but also reduces the chance of pest incidence. Land use types and farming techniques affect bee population. Modern agriculture can be attributed to have destroyed the homes of honeybees. Clean cultivation, elimination of bushy areas and fencerows and high and indiscriminate use of pesticides contribute to reducing number of indigenous bees. Not only the homes for the insects, but also the flowers they visit are destroyed and/ or poisoned.

Bees should be protected from pesticides especially by means of prevention and effective management techniques. Major bee-poisoning incidents in crop production occur when plants are in bloom. Integrated pest management (IPM) and / or organic farming should be highly promoted in order to minimize application of pesticides. Acts, rules and regulations related to bees, bee-products and pesticides and their trade and quarantine should be updated and strictly put to actions.

Conserving honeybees need endeavors by many fronts including measures to preserve the environment, better education, increased research and government support. Collaboration among various stakeholders, including international organizations, research, trade and policy institutes, grass-root community groups and consumers is a key to ensure integrated efforts to such endevior. In addition, national capability should also be developed for access, use, conservation and transfer of relevant technologies in the field. 


\section{REFERENCE}

Dowden, A. O., 1964. The secret life of flowers. The Odyssey Press, New York, pp45.

Hoopingarner, R. A. and G.D. Waller, 1992. Crop pollination. In: Graham J. (ed.). The Hive and the Honeybee. Dadant and Sons. Hamilton, Illinois, pp1043-1082 (Revised edition).

Meeuse, B. J. D., 1961. The story of pollination. New York, Ronald Press, pp243.

Verma, L. R., 1992. Beekeeping and pollination ecology of mountain crops. In: Verma, L. R. (ed.) Honeybees in mountain agriculture. International Centre for Integrated Mountain Development (ICIMOD), Kathmandu, Nepal. 